\title{
Innovations in the Content of Professional Training of Interpreters and Translators in Countries of Europe, the USA and Ukraine: Comparative Analysis
}

\author{
Olesia M. Cherkashchenko ${ }^{1}$, Tetiana M. Vysotska ${ }^{1}$, Svitlana V. Korotkova ${ }^{1}$, Yuliia O. Savina ${ }^{1}$ \& Iryna V. Khurtak ${ }^{1}$ \\ ${ }^{1}$ Translation Department, Electrical Engineering Faculty, Institute of Power Engineering, National TU Dnipro \\ Polytechnic, Dnipro, Ukraine \\ Correspondence: Svitlana V. Korotkova, Translation Department, Electrical Engineering Faculty, Institute of Power \\ Engineering, National TU Dnipro Polytechnic; 19, Dmytra Yavornytskoho av., Dnipro, 49005, Ukraine. E-mail: \\ sveta_korotkova@i.ua
}

Received: June 20, 2019

Accepted: July 16, 2019

Online Published: July 17, 2019

doi:10.5430/ijhe.v8n4p136

URL: https://doi.org/10.5430/ijhe.v8n4p136

\begin{abstract}
The article deals with the analysis of innovations in the content of professional training of interpreters / translators at universities of Europe, the USA and Ukraine. It has been established that at European and American universities the innovation data involves directing professional education of translators and interpreters towards studying CAT-systems within the context of traditional disciplines, specialized disciplines, extracurricular courses, trainings and in the process of students' translation/interpretation traineeship and study placement. Based on the comparative analysis of the curricula for specialists' training in translation/interpretation in European countries, the USA and Ukraine, the conclusion is drawn that in higher education of Ukraine theoretical training traditionally prevails over practical field experience, general classroom hours are not sufficient for students, while Ukrainian universities' curricula lack disciplines aimed at the formation of technological (information, computer) expertise of prospective interpreters and translators. The authors of the article recommend using the experience of western universities on implementing innovations within the content of professional training of interpreters and translators at Ukrainian universities, namely: a) increasing the number of classroom activity hours in practical training of interpretation/translation students by means of reducing extracurricular hours; b) changing the ratio of disciplines of theoretical and practical training of future interpreters and translators in favour of the latter by decreasing the number of theoretical subjects; c) including disciplines aimed at the formation of prospective experts' information competency into the curricula; d) providing both short-term and long-term traineeship in interpreter/translator training programs, preferably at international organizations (enterprises) operating in Ukraine or at foreign companies abroad; e) providing specialization of professional training of interpreters and translators (technical translation, legal translation, economic translation, medical translation, literary translation, etc.).
\end{abstract}

Keywords: interpreters and translators, content of professional training, innovations, curricula, universities of European countries, the USA and Ukraine

\section{Introduction}

The beginning of the third millennium was marked with the transition of the mankind from the post-industrial society to the global information society whose key characteristics are connected with an intensive political and economic interaction between states, a rapid increase of the social and academic mobility of the society, an extensive use of modern information and communication technologies, computing and high technologies in all spheres of life of the world community.

From this perspective, in today's context it is difficult to overestimate the role of an interpreter/translator who appears to be not just a mediator between languages and cultures but a full-fledged player in political, social and economic processes occurring in the modern global world the success of which relies heavily on the level of professionalism of an interpreter/translator.

It is little wonder that the first decades of the 21 st century have witnessed an increasing demand for highly competent interpreters and translators. According to a witty remark made by the famous American journalist Jeffrey Ressner, the demand for training a good many of qualified interpreters and translators in the modern world arises due to and 
despite technological development: "The boom in translation jobs comes because of - and despite - technology" (Ressner, 2007).

Obviously, national systems of higher education whose establishments deal with training professional interpreters and translators should urgently and adequately react to emerging changes in the social demand for interpretation and translation profession of the modern era. This is being debated a lot by national and foreign linguists and educators who are directly involved in the theoretical and practical training of prospective interpreters/translators at universities of Ukraine, the USA and European countries (Amelina \& Tarasenko, 2014; 2016; Berthaud \& Mason, 2018; Kovalevskaitė \& Vaičenonienè, 2015; Christensen, 2011; Doyle, 2003; Durban, 2011; Guerberof, 2009; Ilner, 2010; Panov, 2017, Przybylska, 2012; Pym, 2000; 2012; Rodroguez-Castro, 2018; Su, 2019; Vilanova, 2007; Zygmunt, 2014).

We are confident that nowadays the primary objective in the professional training of interpreters and translators involves a scientific and theoretical development and implementation of relevant innovations in educational process. The innovations, in turn, consist of two interrelated components: a content-related one (fundamental changes in curricula for training interpretation/translation experts taking into account the reality of the contemporary global information society) and a methodological one (search for new forms and techniques to train prospective interpreters/translators using modern information and communication, computing and other technologies).

The framework of a separate scientific article does not allow us describing all the current innovations in professional education of future interpreters/translators in universities' educational process. That is why we will focus on the analysis of innovations in the content field of professional training of interpreters/translators in European countries, the USA and Ukraine.

\section{Method}

Within our research, studies of innovations in the content-related aspect of professional training of interpreters/translators in the present day educational system of Ukraine, the USA and European countries were conducted on the basis of the analysis of curricular and steering documents of different universities involved in training translation and interpretation experts. We also applied the method of comparative analysis with the purpose of identifying the best practices which can be efficiently used in training interpreters/translators at the universities of Ukraine. Moreover, while conducting our research we made use of our own many years' experience in teaching special disciplines for training interpreters/translators at NTU (the National Technical University) Dnipro Polytechnic.

As a result of the analysis of curricula of training prospective interpreters and translators at the universities of Europe and the USA, disciplines have been distinguished which reflect innovations in the contents of professional training of interpretation and translation experts and meet the requirements providing the quality of translation practice in the modern global information world.

The comparative analysis of the contents of European and American curricula of professional education of interpreters and translators with similar curricular of Ukrainian universities allowed us defining areas of concern within the content of training future interpreters/translators in Ukraine.

Since nowadays professional training of interpreters and translators is conducted by hundreds of universities of Europe and the USA as well as by a number of Ukrainian higher educational establishments, in our research we applied the random sampling technique to choose universities for the analysis of their experts training curricula using the principle of "regional diversity". Thus, for example, for the analysis of the contents of curricula of interpreters/translators training in Europe, a few educational establishments were chosen which are situated in the centre, in the north, west and east of this part of the world. A similar principle was applied while selecting universities of the USA and Ukraine. In total, over twenty curricula of bachelors' and masters' training in interpretation and translation at the universities of European countries, the USA and Ukraine were analyzed.

\section{Results and Discussion}

The content of interpreter/translator training at the leading higher educational establishments of Europe and the USA is considerably conditioned by the commitment of their curricula to interpreting and translation service standards, which reflect the demands for interpretation/translation quality and need for formation of interpreters' and translators' relevant competencies (ISO 17100:2015, 2015; ASTM F2575-06, 2006; Sprache, Kultur, Translation (B.A.), n./d.).

The essence of interpreters'/translators' competencies and activities, which are defined by the above standards, suggests that they demonstrate high level of formedness to apply state-of-the-art IT solutions while 
interpreting/translating (Vysotskaya, 2016). Despite the intention of the leading universities of different countries to develop common approaches to the formation of prospective interpreters'/translators' certain professionally important competencies, first of all, the information competence, there are obvious varieties of content of professional training of interpretation/translation experts.

For example, the University of Wisconsin-Milwaukee, includes the "Computer translation" course in the curriculum for training interpreters and translators; the course is compulsory and provides translation skills development based on the use of computer technologies to accelerate translation process and increase its efficiency through automatization of data storage, files analysis, relevant data search and others.

The Undergraduate Program in Translation and Interpretation of the University of Florida includes two disciplines "Written Translation" and "Interpretation", which are necessarily studied by all the students, as well as five other courses which are selected by the students from a list of the eight suggested ones. The most common combinations of the courses selected by students include "Computer-Aided Translation", "Occupational Traineeship" and a few other disciplines of discipline-specific translation, which allows mastering information technologies by prospective interpreters and translators.

The translator and interpreter-training program at Kent State University, Kent, Ohio, involves studying a compulsory discipline "Terminology and Computer Applications for Translators", which focuses on working with translation memory database. The New York University offers "Theory and Practice of Terminology" course to future interpretation/translation experts (Kent State University, 2013).

With the purpose of studying the peculiarities of applying terminology in the process of translating/interpreting texts with the use of information technology support, Babel University, the USA, teaches the students a compulsory course "Text Processing". Its content is aimed at forming and developing the students' skills of quick dictionary creation, parallel arrangement of the original and translated texts on the page, as well as those of processing the main types of texts and using typical software functions for translation.

Certain universities of the USA target their interpreter/translator training at new kinds of operation which are conditioned by topical needs of contemporary market for interpreting and translation services. Thus, translator and interpreter-training programs of many American universities include a course on "Software Localization". It is compulsory at Kent State University, Kent, Ohio, California State University, Monterey Bay. While doing the course, the students learn how web content is created, authorized, formed and published. Using specially equipped computer laboratories, the students practice various operations with live web sites for creating its localized copy. While studying "Introduction to Software and Website Localization" at New York University, the students learn to adapt the software for international markets as well as to translate websites. Babel University offers its students to master "Website Creation". Its content suggests that the students who have completed the course successfully can create their own Intranet websites and understand the Hyper Text Markup Language (HTML), which is essential for website translation. The disciplines which are oriented towards meeting societal demands can also include "Writing Texts for New Media", implemented by Dallas University. In the process, they focus on the practice of creating written forms of texts for networking services (blogs, Wiki, podcasts, Youtube, Twitter).

The University of Chicago trains interpreters/translators on the basis of an integrated program by combining classroom work with components of distance learning. All the students of the University have to study "Translation Instruments" and "Project Management for Translators".

An innovation of Kent State University, Kent, Ohio, which offers the students availability of Master of Business Administration (MBA) dual degree with Master in Translation is of great interest. It is designed for students with a sufficient level of reference for foreign languages who would like to integrate managerial qualities into their translation practice (Kent State University, 2013).

Starting from the 2010s, within the framework of education for vocational purposes, a number of Polish universities introduced topics which refer to using information technologies in translation. Thus, the curriculum of translator and interpreter training at the University of Warsaw for the third-year bachelor students provides mastering the discipline of Translatorics. Its content includes such rather traditional topics as translation definition, classification of translation types, history of translation, concept of equivalence and its evolution, translation strategies and techniques, the translator's competencies. Along with these, a new topic has been added to the above list - "New Trends in Translation Studies": Audio-visual Translation, Localization, Computer-Assisted Translation, which is targeted at students' mastering the technologies of present-day machine assisted translation.

At Adam Mickiewicz University, Poznan, Poland, a translation training program has been developed which is 
divided precisely into theoretical and practical blocks. The practical block includes, apart from the linguistic and industry-specific disciplines, such subjects as "Written Translation Practice", "Translation of Documents for Notarial Certification", "Legal Text Translation", "Language of Economics", "Economic Text Translation", "Commercial Contract Translation", "Technical Text Translation" as well as "Computer-Assisted Translation".

Students at Polish universities continue studying new translation/interpretation technologies while pursuing graduate studies, although they are supposed to constitute an elective part of the curriculum or to be additional opportunities on the courses beyond the curricular.

In particular, within the Master training program for translators/interpreters at Kazimierz Wielki University in Bydgoszcz, the students are provided with free studying of CAT, SDL, Trados Studio and are given a relevant certificate.

Several Polish universities turn their focus towards the organization of practical training of prospective interpreters/translators by giving them an opportunity of traineeship at the establishments which use CAT-systems in their activities. Thus, for ten years Opolski University has been cooperating with Textpartner sp.j., which admits the best graduate philologists-students for individual internship.

This mode of study can be distinguished as a unique opportunity of providing students with industry-specific translation/interpretation practice and their acquiring of knowledge which concerns principles of the use of tools to support translation (CAT tools) as well as methods for processing and preparing the files translated (the so-called engineer files). Due to immediate contacts with the experienced team of Textpartner sp.j. employees, students also learn about translation project management framework, data retrieval methods and procedures concerning language quality assurance, which is performed by using contemporary information technologies.

Polish universities whose interpreter/translator training curricula do not provide courses with the content based on applying information technologies offer their students to study these disciplines within supplementary courses. In particular, the University of Silesia in Katowice organize one-day courses for teaching translation with using CAT-tools which are delivered by certified trainers. The object under study of these courses involves the system of computer-assisted translation system memoQ.

Considering current restrictions related to possible transformation of curricula, one of the ways to compensate for the lack of interpreters'/translators' knowledge and skills required in the current context is to organize and conduct "Interpretation/Translation Workshops". These activities are additional offers targeted at profound mastering of certain components of translator and interpreter-training programs. They are intended both for bachelor and master students, though current interpreters and translators as well as other experts concerned can participate in them as well. Their objectives are deepening and improving competencies which refer to certain aspects of interpretation and translation, insights into new interpretation/translation tools, namely into CAT-systems, and revising for exams for obtaining sworn interpreter/translator qualifications. The enrolment for the participation in the workshops lasts throughout the academic year and classes start after students making minimum capacity are enrolled (the intended number of participants in a group makes 10-20 students). The program of the activities embraces a number of offers, namely: a study course for beginning interpreters/translators, preparatory courses for sworn interpreter/translator candidates, as well as master classes which include communication in foreign languages, translation of economic texts, simultaneous interpretation, and application of the software for translation support - SDL Trados Studio. On completing the course at "Interpretation/Translation Workshops", the participants get relevant certificates.

Lodz International Studies Academy, Poland, adds variety to the training program for future interpreters/translators by offering supplemental areas of specialization, in particular, those in computer-assisted translation, international journalism, country studies and others. The educational programs according to areas of specialization are directed at enhanced studying of disciplines in the sphere of information technologies, economics, international relations, etc.

At Jagiellonian University in Krakow, one of the major disciplines of the study program for translation and interpreting training is "Theory of Translation", which includes the following themes: translation/interpretation as an act of verbal communication, dynamic equivalence, formal equivalence, signs of non-verbal communication and translation/interpretation, theories of translation, translation and meaning of reference (pragmatic, emotional, intra-linguistic), cognitivism and translation theories, comparative analysis and translation, coherence and informativity of the text, classification of translation errors, conference interpretation, translation/interpretation of legal texts and legal services, computer-assisted translation, audio-visual translation, teaching foreign languages and translation/interpretation, European standards for translation services, Copyright Law, certified translation, professional associations of translators and interpreters, translator jobs. As can be seen, a wide range of themes of 
"Theory of Translation" involve computer-assisted translation, and it is worth mentioning that some of them make modules or disciplines at universities of Ukraine.

One of the examples of Czech universities' approach to perspective interpreters'/translators' mastering of information technologies is the experience of Palacký University in Olomouc. There, the first-year translation/interpretation students study "Information Technologies" in the amount of 3 credits in the first semester and 3 credits in the second semester. The given course is targeted at acquiring competencies which concern application of information and communication technologies in translating.

The content of the discipline in the first semester highlights the following themes: introduction to IT equipment, computer infiltration, principles of cyber-security, electronic mail (settings and advanced process control), World Wide Web (web browsers, advanced web search), HTML web-editing, MS Word (integrated document editing). The content of the second semester disciplines includes, in particular, the following themes: creation and formatting of complex presentations in Powerpoint; electronic spreadsheet and graphs in MS Excel; creation, editing and encoding documents in the PDF format, scanning and editing of bit image graphics in Adobe Photoshop; creation of simple database using MS Access; data management for zip-files.

The following stage of mastering knowledge and forming skills of using computer technologies directly in the professional area involves studying the discipline of "Computer-Assisted Translation" by the second-year students. The course is aimed at introducing students to different ways of using computer technologies in translation. In particular, it provides knowledge on general theory of translation based on information technologies and allows forming basic skills of applying various software programs which belong to CAT-systems: Wordfast Classic, Wordfast Pro, Plustools, Kilgray's memoQ, Memsource. The discipline is taught in the autumn semester and is worth 3 credits, which allow for mastering technological operations with documents for translation (scanning and recognizing, import, export, editing), principles of creating computer-assisted thesauri and managing them, basics of working with translation memory database, etc. While studying "Computer-Assisted Translation" in the spring semester (4 credits), they focus on developing skills of working with various software applications for doing machine assisted translation and working with the documents translated. For this purpose, a number of operations are to be completed including those for forming term bases (TB); creating translation memory (TM) database by comparing original texts and their translations; converting different formats of translation memory database; managing translation memory databases in the network environment; translating graphically complicated documents, editing preparing them for desktop publishing (DTP); post-editing machine translation (MT); translation project management. Implementation of the final translation project provides for the development of students' ability to work together in a team and coordinate the course of the operations required for successful completion of a large translation project. Moreover, the students have an opportunity to find out about special tools for localization of the software.

Masters' programs for training interpreters or translators in Vilnius University (n./d.) provide the formation of a more extended number of professional competencies, in particular, such as metacognitive, system, translation/interpreting, information and technology, linguistic, intercultural competencies, as well as a competency of providing translation/interpretation services. Distinguishing an individual information and technology competence, which contributes considerably to structuring expert knowledge and skills of using hardware and software while translating, within the system of professional competencies of prospective interpreters and translators gives evidence of aiming at a whole new level of mastering information technologies while training interpreters/translators.

The Master's program of Vilnius University (n./d.) is attractive for those who, apart from deepening their knowledge and improving translation skills, would like to master localization methods, new technologies of terminology management and translation, skills of managing translation projects.

According to the similar system, future translators'/interpreters' professional competencies are formed at Higher Education Vilnius Business College and Vytautas Magnus University, where 6 credits are allocated for bachelor students' studying CAT-systems and specialized tools for managing information.

We can also consider the Master's study program in "Translation and Localization of Technical Texts" by Kaunas University of Technology to be a unique one in the education market. The peculiarity of this program is that translators are trained entirely to work with computer-aided translation systems which are used for implementing translation projects, localization of software products and web sites. In the process of training, the students master a wide range of software for translation and localization: SDL Trados Studio, Memoq, Omegat, Dejavu, Wordfast, Passolo, Catalyst, Language Studio, Multilizer, Visual Localize. Particular attention is paid to developing skills of working with SDL Trados software products, which are being increasingly used throughout the world both by 
individual translators and translator associations.

Leipzig University offers its students to study "Terminology Studies and Language Technology". Moreover, the students' cognitive processes are directed at studying hardware and software, mastering particular techniques for working with terminology which, first of all, are directed at applying term bases while translating based on computer-aided translation systems. At Saarland University the discipline "Terminology, Language Data Processing, Machine Assisted Translation" is compulsory for future interpreters/translators. There they study theoretical and practical aspects of translation related to application of specialised software, in particular: tools for computer assisted operations with terminology, for machine and computer assisted translation and project management in translation. The discipline under consideration consists of three modules: computer assisted operations with terminology, specific problems of machine and computer assisted translation. Apart from this, studying modules "Professional Translation: Information Technologies and Engineering", "Professional Translation: Economics" suggest using relevant software for managing projects, creating term bases and providing machine assisted translation (Studienführer, 2014).

At Johannes Gutenberg University, Mainz, within the content of the compulsory discipline "Interpretation and Translation Studies" topics "Machine Assisted Translation" and "Translation Memory Systems" are related to studying information technologies in translation.

Cologne University of Applied Sciences offers its bachelor students to analyse auxiliary tools such as electronic database and the Internet within the course "Techniques of Translating Professional Texts". The purpose of the module "Languages and Information Technologies", which is included in the Interpretation and Translation Studies Program of University College Cork, Ireland, is to study software tools and information resources for creating and analysing a text.

The module "Language and Translation Memory" at the University of London is intended to master various themes dealing with application of computer systems for presenting, using, or translating information expressed by the natural language and includes computer-based translation, linguistic resources management and use of terminology.

As for the module "Translation Technology" of the University of London (Middlesex University London, n./d.), it suggests students' acquiring practical experience in dealing with an application toolkit for translation: SDL Trados Multiterm 2014, SDL Trados Studio 2014, memoQ and a number of cloud systems. Combination of theoretical knowledge and its practical implementation through the use of machine assisted translation tools is the basis of the module "Translation of Technical Texts". While studying, the students obtain valuable information from experts and scientists in relevant areas and have an access to special tools and equipment (laboratories and corresponding software such as SDL Trados and Wincaps).

Introducing the module "Use of Technologies in Translation and Interpretation Industry" to the program of training translators and interpreters by British University of Bath contributes to forming the students' system understanding of processing tools which are used in the translation industry.

The module "Translation and Technologies" (Aston University, Birmingham) provides a selection of electronic means to support a professional translator's activities. Students complete practical translation tasks using the computer-aided translation systems with the technology of Translation Memory, machine translation systems, term bases, sub-title editor program and tools of localization. At the American branch of Aston University, formation of computer-assisted translation skills is performed not through a certain discipline, but by integration of the relevant material to the course of "Advanced Level of Translation".

The content of professional training of interpreters and translators at universities of Ukraine is significantly different if compared to similar programs of educational establishments of Europe and the USA. Moreover, Ukrainian programs, unfortunately, are at a disadvantage compared to their western counterparts in regards to quantity and quality.

Thus, most universities of Ukraine offer their students to obtain a profession of an interpreter or translator as an additional option to the main profession of a philologist or a foreign language teacher. Meanwhile at universities where translation/interpretation is a separate specialty there is a considerable lack of proportion between classroom hours for training students and their independent work with the latter prevailing. Moreover, the curricula under analysis provide disciplines which are not immediately related to professional and practical training of prospective translators and interpreters featuring extensive disciplines of the humanities, social and economic sciences, and academic qualification both on compulsory and elective courses of academic programs.

Thus, for example, the curriculum of Sumy State University (n./d.) for bachelors in "Germanic Languages and 
Literature, Including Translation" is designed for 4950 hours of training within 4 years. However, classroom studies involve a little over 2000 hours. Practical training of translators/interpreters is performed due to teaching such disciplines as "History of Translation", "Country Studies", "Theory and Practice of Translation", "Office Activities of Translators", "Aspects of Classical Philology in Translation", "Translation of Scientific and Technical Texts" and others. At the same time, the technological (computer and information) aspect of interpreters' and translators' activities is lacking in the content of the curriculum.

While training master students in translation at Ivan Franko National University of Lviv (n./d.) they offer students to master the following disciplines: "Topical Problems of Cognitive Linguistics", "General Language Science", "Culture of Foreign Languages", "Trends in Foreign Language Development", "Topical Problems of Interpretation and Translation Studies", "Language Philosophy", "Problems of Interpretation" and others. As we can see, the curriculum does not highlight disciplines targeted at forming prospective interpreters' and translators' information competency.

The curriculum for master training with a specialization in "Philology (the English Language)" at Academician Y. Bugay International Scientific and Technical University (n./d.) (course duration of 1.5 years) provides for obtaining qualification of "Philologist", "Higher Educational Establishment Teacher" and the students' mastering fundamental knowledge, two foreign languages, which they can speak fluently using in different fields of expertise related to interpretation and translation. However, within the content of practical training of prospective interpreters/translators, which is represented in the curriculum, only a few disciplines come under notice, namely such as "Translation of Special Industry-specific Terminology", "Oral Bidirectional Translation", "Simultaneous Interpretation", "History and Theory of Translation". The only discipline available in the curriculum of the University which contributes to forming the students' information and technology competency is "Innovative Information Technologies in Translation" in the amount of 3 credits.

The students enrolled in the Master's degree course of "Translation" at V. N. Karazin Kharkiv National University (n./d.) are offered to master a profession of the translator/interpreter by studying such disciplines as "History and Theory of Translation", "Theory of Translation as Intercultural Communication", "Fundamentals of the Editing Theory", "Fundamentals of Cognitive Semantics", "Translation and Interpreting Practice".

In terms of innovations within the content of professional training of interpreters and translators, the one which is the most similar to western specialist training programs is that curriculum of the National University of Life and Environmental Sciences of Ukraine in the amount of 90 credits (Nikolaienko, 2017). According to the curriculum, the students master a profession of the translator/interpreter through studying the following disciplines: "Communicative Strategies of the Foreign Language", "Technique of Interpretation/Translation", "Information Technologies in Translation Practice", "Translation Editing of Agricultural Texts", "Interpretation and Translation of Specialised Texts". Within the framework of studying "Information Technologies in Translation Practice", the students are offered to comprehend the following themes: information translation environment; use of information technologies at the stages of preparing, understanding, and interpreting the English scientific and technical text, information and reference search, creating the target text and selecting translation approximations and equivalents, translation output assurance; present day systems of computer-based translation and machine assisted translation, CAT systems.

Generally speaking, the content of professional translator/interpreter training in many higher educational establishments of Ukraine is to a greater or lesser extent similar: traditional prevalence of academic training over practical training, insufficient quantity of students' classroom study hours, lack or insufficient quantity of disciplines targeted at formation of technology (information, computer) competency of prospective interpreters and translators.

As recommendation on implementation of innovations in the content of professional training of interpreters/translators in institutions of higher education of Ukraine, the following can be offered:

1. To increase the amount of classroom studies in practical training of students in professional interpretation and translation by means of reducing extracurricular hours.

2. To change the ratio of disciplines of theoretical and practical training of prospective interpreters and translators to the advantage of the latter due to decreasing the number of theoretical courses.

3. To include disciplines aimed at forming prospective experts' information competency into the curricula of interpreter/translator training at universities of Ukraine.

4. To involve both short-term interpretation/translation practical training and long-term internship of students, preferably, at international organisations (enterprises) operating in Ukraine or foreign companies abroad when 
developing study programs for translation and interpreting training.

5. To provide specialization of professional training of interpreters and translators (technical translation, legal translation, economic translation, medical translation, literary translation, etc.).

\section{Conclusions}

The analysis of innovations in the content of professional training of interpreters and translators at higher educational establishments of Europe and the USA allowed synthesizing their tendencies, specifying the essence of these innovations as well as revealing common approaches of the universities of different countries dealing with preparing experts in this field to considering the demands of the contemporary global information society for the quality of the interpreter's/translator's professional competencies. At large, the innovations refer to commitment of professional training of interpreters/translators to studying CAT systems within the framework of traditional disciplines, specialized disciplines, extracurricular courses, trainings and in the process of students' translation/interpretation traineeship and study placement.

Therefore, the conducted research showed that innovations in the content of professional training of interpreters and translators at universities of Europe and the USA essentially resolve themselves to the following aspects:

- upgrading the disciplines of curricula for bachelor and master training with certain modules, sections, themes which refer to application of modern information technologies in translation;

- organizing interpreter/translator practical training in companies whose activities are related to the use of CAT systems and other information technologies;

- offering students to enrol in courses on CAT systems on a gratuitous basis or/and on a fee basis with an option to collect a certificate based on the results of taking relevant exams;

- considering new types of the interpreter's/translator's activities which are based entirely on application of modern specialised software products;

- conducting trainings aimed at students' mastering the practical component of using CAT systems when achieving the interpreter's/translator's objectives;

- opening new specialties which provide for training translators to perform their professional activities entirely with the use of computer-aided translation system.

The research perspectives can be related to search for ways of implementing the innovative experience of European countries and the USA at the Ukrainian universities which provide efficient professional training of interpreters and translators.

\section{References}

Academician Y. Bugay International Scientific Technical University. (n./d.). Specialty “Philology”. Retrieved March 3, 2019, from https://istu.edu.ua/en/filolohiya/

Amelina, S. M., \& Tarasenko, R. O. (2014). Information technology component in the training of future translators in UK universities. Studies in comparative education, 2-3, 169-174.

Amelina, S., \& Tarasenko, R. (2016). Innovations in formation of informational competence of translators: experience of foreign Universities. Scientific Bulletin of National University of Life and Environmental Sciences of Ukraine, 140, 344-348.

ASTM F2575-06. (2006). Standard Guide for Quality Assurance in Translation. West Conshohocken, PA: ASTM International.

Berthaud, S. \& Mason, S. (2018). Embedding reflection throughout the portgraduate transation curriculum: using Communities of Practice to enhance trainging. The Interpreter and Translator Trainer, 12, 388-405. https://doi.org/10.1080/1750399X.2018.1538847

Christensen, T. P. (2011). Studies on the Mental Processes in Translation. Memory assisted Translation - the State of the Art. transCkom, 4(2), 137-160.

Doyle, M. S. (2003). Translation Pedagogy and Assessment: Adopting ATA's Framework for Standard Error Marking. The ATA Chronicle, 32(11), 21-28.

Durban, C. (2011). Translation. Getting it right. A guide to buying translation. Retrieved March 3, 2019, from https://www.atanet.org/publications/Getting_it_right.pdf 
Guerberof, A. (2009). Productivity and Quality in the Post-editing of Outputs from Translation Memories and Machine Translation. Localisation Focus, 7(1), 11-21.

Ilner, A. O. (2010). Training of translators and interpreters in Russia and abroad: a comparative analysis. Education and science, 8(76), 65-70.

ISO 17100:2015. (2015). Translation Services - Requirements for translation services. London: British Standards Institution.

Ivan Franko National University of Lviv. (n./d.). Master (Philology). Retrieved March 3, 2019, from http://lingua.Inu.edu.ua/en/academics/master

Kent State University. (2013). Kent State University Catalog 2013-2014. Retrieved March 3, 2019, from http://catalog-archive.kent.edu/archive/catalog/2013/as/ug/eng.html

Kovalevskaitė, J., \& Vaičenonienè, J. (2015). The use of technology in teaching and learning translation: student opinion survey. Sustainable Multilingualism, 7, 160-180. https://doi.org/10.7220/2335-2027.7.9

Middlesex University London. (n./d.). Translation (Business and Legal) MA/PGDip. Retrieved March 3, 2019, from http://www.mdx.ac.uk/courses/postgraduate/translation/Business_Legal_Translation.aspx

Nikolaienko, S. M. (Ed.). (2017). Master curricula and training programs 2017-2018 academic year. Retrieved March 3, 2019, from https://nubip.edu.ua/sites/default/files/u34/9241_katalog_magprogram_angl_2017_0.pdf.

Panov, S. F. (2017). Theoretical and methodical foundations of professional training of technical translators at higher educational establishments. Doctoral thesis. Kyiv.

Przybylska, R. (2012). What future for practical or applied linguistics? POLONICA, 33, 25-31.

Pym, A. (2000). Innovation in translator and interpreter training. Report on an on-line symposium. Across Languages and Cultures, 1(2), 209-273. https://doi.org/10.1556/Acr.1.2000.2.5

Pym, A. (2012). Training Translators. In The Oxford Handbook of Translation Studies. Oxford: Oxford University Press. https://doi.org/10.1093/oxfordhb/9780199239306.013.0032

Ressner, J. (2007, January 12). Translation Nation. Time. Retrieved March 3, 2019, from http://www.time.com/time/magazine/article/0,9171,1576836,00.html.

Rodroguez-Castro, M. (2018). An integrated curricular design for computer-assisted translation tools. The Interpreter and Translator Trainer, 12, 355-374. https://doi.org/10.1080/1750399X.2018.1502007

Sprache, Kultur, Translation (B.A.). (n./d.). Johannes Gutenberg-Universität Mainz. Retrieved March 3, 2019, from https://www.studium.uni-mainz.de/bachelor-sprache-kultur-translation/

Studienführer. (2014). Translation Bachelor of Arts: Zentrale Studienberatung. Leipzig: Universität Leipzig.

Su. W. (2019). Inteepreting quality as evaluated by peer students. The Interpreter and Translator Trainer, 13, 177-189. https://doi.org/10.1080/1750399X.2018.1564192

Sumy State University. (n./d.). Translation speciality. Retrieved March 3, 2019, from http://gf.sumdu.edu.ua/en/bachelor-s-degree.html

V. N. Karazin Kharkiv National University. (n./d.). Bachelor's Degree Programs. Retrieved March 3, 2019, from http://foreign-languages.karazin.ua/academics/BS

Vilanova, S. (2007). The impact of translation memories on the target text: interferences and shifts. Minor Dissertation. Tarragona.

Vilnius University. (n./d.). Degree system. Retrieved March 3, 2019, from https://www.vu.lt/en/studies/academic-information/degree-system

Vysotskaya, T. (2016). Students-translators professional competence development: theoretical outline. In Proceedings of the International Scientific Conference: Society. Integration. Education. Rēzeknes: Rēzeknes Tehnologiju akadēmija.

Zygmunt, I. (2014). Does the translation have a future? Języki w Europie, 2, 23-26. 